\title{
Prospects still bad for space science launches
}

Washington

$D_{R}$ Burton Edelson, associate administrator for space science and applications for the National Aeronatics and Space Administration (NASA), last week made public revised plans for space science missions in the aftermath of the Challenger accident. While the two-year delay to shuttle launches and the subsequent lower launch rate mean that many missions will be postponed or cancelled, Edelson is determined that science missions should be fairly represented when launches resume. $\mathrm{He}$ said it would be "ruinous" if NASA had to use money from its science budget to build the unmanned rockets now planned. Edelson also announced new initiatives to restore the enthusiasm of university researchers whose shuttle experiments have been delayed.

Edelson, who was addressing a meeting of the American Astronautical Society, said that NASA now plans some 63 shuttle missions between 1988 (when flights should resume) and 1992, although he added that some thought that schedule

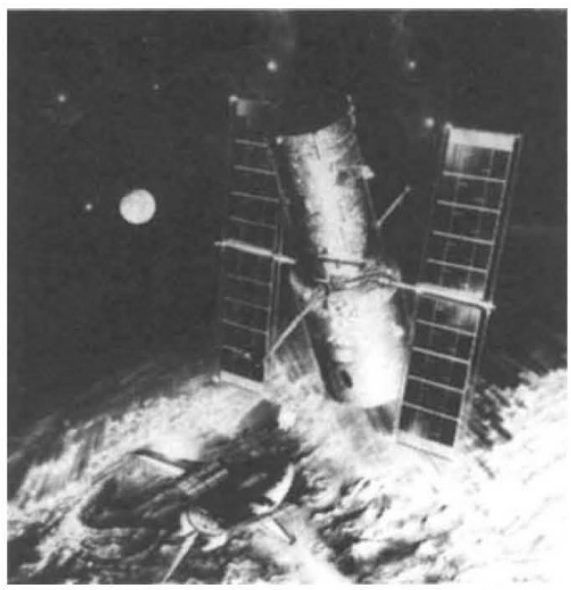

Priority but still a distant prospect. The Hubble telescope.

optimistic. This represents a major reduction, since before the Challenger accident, 145 missions were planned by 1992 . Of the 80 lost flights, 31 were to have been primarily space science missions, now only 19 science missions will fly before 1992 .

Acknowledging that his news was not good, Edelson restated NASA's commitment to ensure that space science missions should occupy at least a third of all shuttle flights. He also said that launching the Hubble Space Telescope remains a top priority.

Edelson's programme ("some tens of millions of dollars") for maintaining the health of the university research community includes more support for data analysis and sub-orbital research; for developing new instruments and small payloads; for using other NASA flight projects to give "piggyback" launches to science projects; and for developing new cooperative programmes with domestic and international partners.

Edelson said that eleven major Spacelabtype shuttle flights that were to have flown between 1987 and 1989 had been on the list for cancellation, but that four have now been identified as launch candidates (though only three are likely to go before
1990). These are the Earth Observation Mission, a joint effort with the European Space Agency, now renamed Atlas; Astro, an ultraviolet observatory; the International Microgravity Laboratory; and SLS - 1, a dedicated Spacelab life sciences flight. But even those that do fly are likely to suffer delays of at least two and a half years. Between 8 and 10 materials science laboratory payloads and about 12 Spartan payloads will also now not fly before 1990 .

Edelson also said that NASA's recent decision to use Expendable Launch Vehicles (unmanned rockets) as well as the shuttle means that as many as 8 of the 145 missions planned before 1992 could be launched this way. But he gave a stern warning that if NASA is to procure new unmanned rockets, it would need extra funds for the purpose. So far, Congress has ducked the issue.

\section{Reproductive technology}

\section{Ethical guidelines announced}

\section{Washington}

THE American Fertility Society this week published comprehensive guidelines on the uses of new reproductive technology, including in vitro fertilization and the freezing of embryos and gametes. The guidelines are the first attempt in the United States to achieve a broad professional consensus on the ethical issues raised by the new technology. The elevenmember ethics committee which drew them up includes many of the well-known names in the field, under the chairmanship of Howard Jones of Johns Hopkins University School of Medicine. Although the society cannot enforce compliance, its 10,000 members are likely to respect the guidelines.

The guidelines appear as a special supplement to the September 1986 issue of the society's journal Fertility and Sterility. The committee finds no overwhelming ethical objection to any of the reproductive techniques now being considered, but warns that some should still be considered as experimental and subject to special scrutiny by local institutional review boards. It asks the Fertility Society to press for an expanded national debate to include other groups, including the recently inaugurated Congressional biomedical ethics board.

The committee also supports research on the new techniques provided it is backed up with sound policy to protect individual freedom and to gain informed consent. For research on human pre-embryos (a term it advocates for the zygote up to the 8 -cell stage), the committee advocates setting a time limit so that the pre-embryo is destroyed 14 days after fertilization. This is the limit voluntarily adopted in Britain and in Australia.

The committee makes a strong call for the Department of Health and Human Services to abandon its present de facto moratorium on supporting research involving human in vitro fertilization or embryo transfer. The department's regulations forbid it from supporting any such research that has not been approved by its Ethics Advisory Board; but the board was disbanded in 1980, and its 1979 recommendation that in vitro fertilization research is acceptable under certain conditions has not been acted on. There are also statutory limitations imposed by congress prohibiting federal funds from being used for similar research, with the result that research is concentrated in private clinics and hospitals.

The committee rules that techniques such as in vitro fertilization and surrogate motherhood should be considered only when parents are unable to produce children and not merely for convenience. But although maintaining that a stable heterosexual couple provides the best environment for child-rearing, the committee would not exclude the use of the techniques for others who may want children.

Besides simple in vitro fertilization, the committee considers that the use of donor pre-embryos and the cryopreservation of sperm would be acceptable. But it says that uterine lavage as means of obtaining pre-embryos for transfer should be regarded as a clinical experiment and so subject to full research approval requirements; similarly, cryopreservation of preembryos and eggs is seen as premature for general use but a valid topic for research. Surrogate motherhood, about which the committee has "serious reservations", should also be considered experimental. But the committee stresses that its recommendations should be subject to change in the light of public debate. Tim Beardsley 